\title{
Reply to: Fatih Canan "The relationship between internet addiction and eating disorders"
}

\author{
Ahmet Hamdi Alpaslan ${ }^{1}$
}

Received: 8 August 2015/ Accepted: 10 August 2015/Published online: 27 August 2015

(C) Springer International Publishing Switzerland 2015

\section{Dear Editor,}

Thank you for providing the opportunity to reply to Dr. Canan' Letter to the Editor [1], written with respect to our article 'The association between internet addiction and disordered eating attitudes among Turkish high school students'.

We thank Dr. Canan for his interest in our study. We are grateful for the insightful comments to our manuscript and we are happy to respond to his comments as follows.

As it can be seen, we have cited the study conducted by Canan et al., (reference \#6). 'In a very recent study conducted in Turkey among high school students, a significant positive correlation was found between Body Mass Index (BMI) and the Internet Addiction Test (IAT) scores [2]. It was not our intention to advocate that our article is the just first study, which is investigating the relationship between IA and disordered eating attitudes (DEAs) in our country. Our aim was drawing the readers' attention to the paucity of research in this area.

Kindly, we would like to revise our statement as 'there have been a few studies investigating the relationship between IA and DEAs in our country' in an erratum notice $[3,4]$.

\section{Compliance with ethical standards}

Conflict of interest The corresponding author states that there is no conflict of interest.

Ethical approval This article does not contain any studies with human participants performed by any of the authors.

Informed consent This study does not involve human or animal subjects.

\section{References}

1. Canan F (2015) The relationship between internet addiction and eating disorders. Eat Weight Disord. doi:10.1007/s40519-0150203-2

2. Alpaslan AH, Kocak U, Avci K, Uzel Tas H (2015) The association between internet addiction and disordered eating attitudes among Turkish high school students. Eat Weight Disord. doi:10.1007/s40519-015-0197-9

3. Canan F, Yildirim O, Ustunel TY, Sinani G, Kaleli AH, Gunes C, Ataoglu A (2014) The relationship between internet addiction and body mass index in Turkish adolescents. Cyberpsychol Behav Soc Netw 17:40-45. doi:10.1089/cyber.2012.0733

4. Celik CB, Odacı H, Bayraktar N (2015) Is problematic internet use an indicator of eating disorders among Turkish university students? Eat Weight Disord 20:167-172. doi:10.1007/s40519014-0150-3
Ahmet Hamdi Alpaslan

ahmethamdialpaslan@yahoo.com

1 Faculty of Medicine, Afyon Kocatepe University, Afyon, Turkey 